Check for updates

Cite this: RSC Adv., 2019, 9, 13933

\title{
Unique stabilizing mechanism provided by biocompatible choline-based ionic liquids for inhibiting dissociation of inactivated foot-and- mouth disease virus particles
}

\author{
Xuan Lin, ${ }^{\text {ab }}$ Yanli Yang, ${ }^{\text {a }}$ Shuai Li, ${ }^{\text {ab }}$ Yanmin Song, ${ }^{\text {ab }}$ Guanghui Ma, (D) a Zhiguo Su*a \\ and Songping Zhang (D) *a
}

Inactivated virus and virus-like particles (VLPS) are important classes of biopharmaceuticals for vaccines, immunotherapy and oncotherapy. Their complex particle structures are easily denatured during processing and storage, leading to loss in their biofunctionality. Ionic liquids (ILs) as stabilizing excipients have garnered interest in protein-based pharmaceutical research, but their stabilizing capacity for inactivated virus antigens remains unknown. Here, three biocompatible choline-based ILs, including $[\mathrm{Cho}]\left[\mathrm{H}_{2} \mathrm{PO}_{4}\right],[\mathrm{Cho}][\mathrm{Cl}]$, and [Cho] $\left[\mathrm{SO}_{4}\right]$, were tested as potential stabilizers for the inactivated foot-andmouth disease virus (iFMDV), which are extremely unstable virus particles easily dissociating into smaller pentamers named $12 \mathrm{~S}$. Based on differential scanning fluorimetry technology for thermal stability analysis, together with high-performance size-exclusion chromatography for quantitative determination of $146 \mathrm{~S}$, it was found that $[\mathrm{Cho}][\mathrm{Cl}]$ and $[\mathrm{cho}]\left[\mathrm{SO}_{4}\right]$ can improve the thermo- and long-term storage stability of iFMDV particles, while $[\mathrm{Cho}]\left[\mathrm{H}_{2} \mathrm{PO}_{4}\right]$ showed a destabilizing effect. Animal experiments indicated that the immunogenicity of iFMDV antigens was not attenuated in all three ILs. By monitoring the microenvironmental $\mathrm{pH}$ of the virus particles in different ILs, a relatively lower proton intensity was observed in $[\mathrm{Cho}][\mathrm{Cl}]$ and $[\mathrm{Cho}]\left[\mathrm{SO}_{4}\right]$ than in buffers and $[\mathrm{Cho}]\left[\mathrm{H}_{2} \mathrm{PO}_{4}\right]$. Therefore, the stabilizing mechanism was supposed to be mainly due to suppression of protonation of histidine residues in the inter-pentamer interface of virus particles in $[\mathrm{Cho}][\mathrm{Cl}]$ and $[\mathrm{Cho}]\left[\mathrm{SO}_{4}\right]$, which is distinct from the mechanism reported for other proteins with relatively simple structures. The results suggest that the choline-based ILs with appropriate anions are promising stabilizing excipients for iFMDV or other vaccine antigens.

rsc.li/rsc-advances

products. Protection of the structural integrity is very important to the efficacy and safety of these biopharmaceuticals.

Inactivated foot-and-mouth disease virus (iFMDV) is

Biomacromolecules with complex assembly structures such as virus and virus like particles (VLPs) are playing more and more important roles in the development of vaccines, immunotherapy and oncotherapy. ${ }^{1,2}$ These particulate molecules are gigantic in size and often contain many subunits and domains assembled together by disulphide or non-covalent bonds. ${ }^{3}$ When being used as pharmaceuticals, the correct assembly structures must be guaranteed to provide ideal biological activities. However, in a real situation of production and storage, liquid shear, $\mathrm{pH}$, ionic strength and temperature change are unavoidable, resulting in structure change of the

\footnotetext{
${ }^{a}$ State Key Laboratory of Biochemical Engineering, Institute of Process Engineering, Chinese Academy of Sciences, Beijing 100190, PR China. E-mail: zgsu@ipe.ac.cn; spzhang@ipe.ac.cn

${ }^{b}$ University of Chinese Academy of Sciences, Beijing 100049, PR China
} is a highly contagious disease in cloven-hoofed animals such as cattle, swine, sheep and goats. ${ }^{4}$ However, the intact iFMDV having sedimentation coefficient of $146 \mathrm{~S}$ is sensitive to solution conditions, the assembly is easily disassembled by mild heating or at low $\mathrm{pH}^{5,6}$ Significant dissociation has been reported during purification, ${ }^{7,8}$ storage in solution, ${ }^{5}$ and even after adjuvanted into oil-emulsions. ${ }^{9}$ Such denaturation not only increase the production cost but also reduce products quality, even cause failure in vaccination. Attempts have been made to improve the stability of iFMDV by modifying FMDV particles with formaldehyde crosslink or by acid-resistant mutants. ${ }^{\mathbf{1 0}}$ However, such changes may alter the immunogenicity of antigen although with higher stability in vitro. Physical stabilization by appending excipients is a more general strategy, and has been successfully applied to a lot of virus and VLPs.,.$^{511-13}$ 
Ionic liquids (ILs) are a popular class of organic salts with an organic cation and organic/inorganic anion that are typically liquid below $100{ }^{\circ} \mathrm{C} .{ }^{14}$ They have been widely used in various chemical and biological technologies such as catalysis, solubilisation, and organic synthesis due to their inimitable properties such as high thermal stability and enormous diversity. ${ }^{15}$ Recently, ILs have garnered immense interest in pharmaceutical applications in active pharmaceutical ingredients, drug delivery systems, and also have been demonstrated with great potentials as stabilizing excipients for protein therapeutics. For instance, the biocompatible ILs based on the choline cation enhance the thermostability of enzymes, interleukin-2 (IL-2), monoclonal antibodies (mAbs), and insulin. ${ }^{16-19}$ Imidazoliumbased ionic liquids $[\mathrm{Bmim}][\mathrm{Br}]$ was found to inhibit aggregation of insulin. ${ }^{20}$ Ammonium-based protic ionic liquid triethylammonium dihydrogen phosphate (TEAP) can act as a stabilizer and refolding additive for Succinylated Con A. ${ }^{21}$ Besides protein with relative simple structure, protic ILs, EaMs, was found to significantly enhance the half-life of tobacco mosaic virus (TMV), ${ }^{22}$ suggesting the possibility of stabilizing complex assembly structures by ILs. However, the stability of inactivated virus antigen, like iFMDV, become even worse, the stabilizing capacity of ILs for such kind of complex assembly remains unknown, and there are also concerns on the possible influence of ILs on the in vivo immunogenicity of the virus antigens.

In this study, we investigated the stabilization of the highly unstable iFMDV by three biocompatible choline-based ILs, $[\mathrm{Cho}]\left[\mathrm{H}_{2} \mathrm{PO}_{4}\right]$, [Cho $][\mathrm{Cl}]$, and $[\mathrm{Cho}]\left[\mathrm{SO}_{4}\right]$. Choline has been recognized by the Food and Drug Administration as generally regarded as safe ingredients. ${ }^{19}$ Choline-based ILs are also regarded with good biocompatibility and safety. ${ }^{19}$ To evaluate stability of FMDV, the differential scanning fluorimetry (DSF) technology was employed for thermal stability analysis. Dissociation of $146 \mathrm{~S}$ into $12 \mathrm{~S}$ was detected and quantified by highperformance size-exclusion chromatography (HPSEC). Circular dichroism spectroscopy (CD), transmission electron microscopy (TEM), and animal experiment was performed to detect changes of secondary structure, particle morphology, and immunogenicity that may induced by ILs. Finally, the stabilizing mechanism by choline-based ILs was discussed based on detection of microenvironmental $\mathrm{pH}$ around iFMDV.

\section{Experimental methods}

\section{Materials}

Three ionic liquids, $[\mathrm{Cho}]\left[\mathrm{H}_{2} \mathrm{PO}_{4}\right],[\mathrm{Cho}][\mathrm{Cl}]$ and $[\mathrm{Cho}]\left[\mathrm{SO}_{4}\right]$, were purchased from Yulu Fine Chemical (Lanzhou, China). Purities quoted by the manufacturers were $>98 \%$ for these ionic liquids. Two fluorescent dyes, SYPRO Orange $5000 \times$ and fluorescein isothiocyanate (FTIC), were purchased from SigmaAldrich (USA). All other reagents were analytical grade and all solutions were prepared using Mill-Q grade water (Millipore, USA).

Inactivated FMDV $\mathrm{O}$ strain supernatant was provided by Lanzhou Veterinary Research Institute (Chinese Academy of Agricultural, China). The virus was propagated in BHK-21 cell at industrial scale and inactivated by binary ethylenimin to obtain iFMDV. The iFMDV $146 \mathrm{~S}$ was firstly purified by hydrophobic interaction chromatography (HIC) as described in our previous study. ${ }^{8}$ To further remove residual impurities and displace the background buffer, the elutes from HIC were added with $8 \%(\mathrm{w} /$ v) PEG 6000 and standing at $4{ }^{\circ} \mathrm{C}$ overnight. The $146 \mathrm{~S}$ was precipitated and collected by centrifugation at $6000 \times \mathrm{g}$ for $20 \mathrm{~min}$. Thereafter, the $146 \mathrm{~S}$ was resuspended in $\mathrm{pH} 7.5 \mathrm{or} \mathrm{pH}$ 7.3 PBS (20 mM sodium phosphate buffer, $0.15 \mathrm{M} \mathrm{NaCl}$ ), sterile filtered by $0.22 \mu \mathrm{m}$ filter (Millipore, USA) and was stored at $4{ }^{\circ} \mathrm{C}$ before use.

\section{Quantification of 146S by HPSEC}

Concentration of intact iFMDV $146 \mathrm{~S}$ was quantified and dissociation was monitored by high-performance size-exclusion chromatography (HPSEC). ${ }^{23}$ The HPSEC analysis was performed on a TSK G4000 SWXL $(300 \times 7.8 \mathrm{~mm}$, I.D. $)$ column (TOSHO, Japan) using an Agilent 1100 series system (Agilent, USA), equipped with a degasser and variable wavelength detector with UV monitoring at $259 \mathrm{~nm}$. For each measurement, $100 \mu \mathrm{L}$ of sample was injected and eluted at $0.6 \mathrm{~mL} \mathrm{~min}^{-1}$. The mobile phase was $50 \mathrm{mM}$ phosphate buffer ( $\mathrm{pH} 7.2$ ) containing $100 \mathrm{mM} \mathrm{Na} \mathrm{SO}_{4}$. Each measurement was repeated for three times. For quantification, the peak area of iFMDV at $259 \mathrm{~nm}$ was linearly proportional to iFMDV concentration, with $R^{2}=0.996$ over the tested range between 0 and $100 \mu \mathrm{g} \mathrm{mL}^{-1}$. Therefore, the iFMDV concentration in testing samples could be calculated from the peak area at $259 \mathrm{~nm}$ according to the calibration curve.

\section{Differential scanning fluorimetry (DSF) of iFMDV in ILs}

DSF of iFMDV in different ILs was performed on an ABI 7500 Fast RT-PCR instrument (Applied Biosystems, USA) to study the effect of ILs on the thermal stability of iFMDV. Before detection, all ILs were diluted using $\mathrm{pH}$ 7.5 PBS to a final concentration between $0-4 \mathrm{M}$, and the $\mathrm{pH}$ was adjusted to $\mathrm{pH} 7.5$ by $4 \mathrm{M} \mathrm{NaOH}$ or $2 \mathrm{M} \mathrm{HCl}$. Then the diluted ILs were mixed with $0.5 \mathrm{mg} \mathrm{mL}^{-1}$ $146 \mathrm{~S}$ at a volume ratio of $1: 1$ to a final ILs concentration of 0 $2 \mathrm{M}$ and $146 \mathrm{~S}$ concentration of $0.25 \mathrm{mg} \mathrm{mL}^{-1}$, respectively. For DSF analyses, $0.2 \mu \mathrm{L}$ of Sypro Orange dye pre-diluted for 25 -fold in water $(\mathrm{v} / \mathrm{v})$ was added into $19.8 \mu \mathrm{L}$ of the iFMDV-ILs mixtures, thereafter were all loaded to a 96-well polypropylene plate (Applied Biosystems, USA). The plate was heated from 25 to $95{ }^{\circ} \mathrm{C}$ at a scan rate of $1^{\circ} \mathrm{C} \mathrm{min}^{-1}$, and three repeated measurements were performed for each sample. The transition midpoint temperature $\left(T_{\mathrm{m}}\right)$ was determined using Origin 8.0 software according to the minimum of the negative first-order derivative function $[\mathrm{d}(\mathrm{RFU}) / \mathrm{d} T]$ of the fluorescence signal.

\section{Dynamic light scattering analysis}

Dynamic light scattering (DLS) analysis was performed on a Malvern ZetasizerNano ZS (Malvern Instruments, Southborough, Massachusetts) to measure the hydrodynamic size (diameter) of iFMDV particles in pH 7.5 PBS and in 2 M ILs. A minimum of three measurements were performed for each sample, and the results were expressed in number-weighted size distribution number (\%). 


\section{Circular dichroism spectroscopy and transmission electron microscopy}

Circular dichroism spectroscopy (CD) and transmission electron microscopy (TEM) were performed to detect changes of secondary structure and particle morphology may have induced by ILs.

Far-UV CD spectra were obtained with a Jasco J-810 spectropolarimeter (Jasco, USA) using a bandwidth of $2.0 \mathrm{~nm}$ and a cell of $0.1 \mathrm{~mm}$ path length over the wavelength range from 200 to $280 \mathrm{~nm}$. The spectropolarimeter was purged sufficiently with pure nitrogen before starting the instrument. Each spectrum was baseline-corrected, and the final plot was taken as an average of three accumulated plots. The concentration of iFMDV in this experiment was $0.125 \mathrm{mg} \mathrm{mL}^{-1}$. Each measurement was repeated for three times.

The particle morphology of iFMDV was studied by Philips FEI Tecnai 20 TEM (Royal Philips Electronics, Amsterdam). The iFMDV with ILs were applied to a 400 mesh copper grid, airdried, and stained with $1 \%$ uranyl acetate before TEM characterization.

\section{Determination of immunogenicity of iFMDV in ILS}

To evaluate the effect of ILs on immunogenicity of iFMDV, Balb/c mice were vaccinated with iFMDV $146 \mathrm{~S}$ in different kinds of ILs. A total of $30 \mathrm{Balb} / \mathrm{c}$ female mice, aged between 6 and 8 weeks purchased from Beijing HFK Bioscience Co., Ltd (Beijing, China), were randomly divided into 5 groups $(n=6$ per group). To prepare FMDV vaccines, $80 \mu \mathrm{g} \mathrm{mL}^{-1}$ of $146 \mathrm{~S}$ in $0.5 \mathrm{M}$ of the three ILs or in PBS at pH 7.5 were mixed with Montanide ISA 206 (Seppic, France) at a volume ratio of $1: 1$ by vortex mixer, respectively. As a negative control, the $146 \mathrm{~S}$ was disassembled into $12 \mathrm{~S}$ by heating at $56^{\circ} \mathrm{C}$ for $1 \mathrm{~h}$ before the same operation. For each group, the mice were immunized subcutaneously with $100 \mu \mathrm{L}$ dose of the five vaccines on days 0 and 14. Two weeks after the second immunization, all mice were bled from orbit for detecting antibody against FMDV. The titers of FMDV-specific antibody in mice serum were determined by liquid phase blocking ELISA according to protocols provided by Kit for detecting antibodies of Foot and Mouth Disease Virus Type $O$ (Lanzhou Veterinary Research Institute. CAAS). Briefly, a 2-fold dilution of serum was generated from $1: 8$ to $1: 1024$, and $75 \mu \mathrm{L}$ diluted serum was mixed with $75 \mu \mathrm{L}$ iFMDV antigen in 96-well plates and incubated overnight at $4{ }^{\circ} \mathrm{C}$. Then, $100 \mu \mathrm{L}$ mixture was transferred to microplates precoated with rabbit anti-FMDV capture serum and incubated at $37{ }^{\circ} \mathrm{C}$ for 1 hour. After washing, HRP-conjugated rabbit anti-guinea pig IgG was added at $1: 2000$ and incubated at $37^{\circ} \mathrm{C}$ for 1 hour. The plates were washed and incubated with substrate for 10 minutes at room temperature. Colour development was stopped with stop solution. Optical density of the ELISA plates was read at $492 \mathrm{~nm}$. All animals were treated according to the regulations of Chinese law and the local Ethical Committee.

\section{Detection of microenvironmental pH of iFMDV}

The microenvironmental $\mathrm{pH}$ around iFMDV was detected by a pH sensitive fluorescent dye FITC. iFMDV particles were fluorescently labeled with $0.125 \mathrm{mg} \mathrm{mL}^{-1}$ FITC overnight at $4{ }^{\circ} \mathrm{C}$, and unbounded FITC molecules were removed by a G25 desalting column (GE Healthcare, USA). The FITC labeled iFMDV was then placed in phosphate buffer with certain $\mathrm{pH}$ from 5.5 to 8.0. The fluorescence spectra of the iFMDV in different $\mathrm{pH}$ was measured on a Hitachi F-4500 fluorescence spectrophotometer (Hitachi, Japan) with excitation at 498 and $450 \mathrm{~nm}$, and emission at $520 \mathrm{~nm}$, respectively. A calibration curve of the ratio of emission intensity excited at $498 \mathrm{~nm}$ and $450 \mathrm{~nm}$ against the $\mathrm{pH}$ was established. By measuring the intensity ratio of excitation at 498 and $450 \mathrm{~nm}$ of the iFMDV in different ILs with identical bulk solution $\mathrm{pH}$ of 7.3, the microenvironmental $\mathrm{pH}$ surrounding iFMDV in ILs were determined from the calibration curve. Each measurement was repeated for three times.

\section{Statistical analysis}

Data analysis was performed with Origin and GraphPad Prism software and presented as mean with standard deviation (SD). Statistical significance of difference was determined by the unpaired Student's $t$-test. $P$ values of less than 0.05 were considered statistically significant.

\section{Results and discussion}

\section{Thermostability of iFMDV in ILs detected by DSF}

Differential scanning fluorimetry (DSF) analysis were performed to assess the thermostability of iFMDV in the three cholinebased ILs. As shown in Fig. 1, the thermal scanning of iFMDV showed two transitions: the first induced a small increase in fluorescence intensity and the second induced a large increase. The first-order derivative of the fluorescence signal exhibited two $T_{\mathrm{m}}$ around $50{ }^{\circ} \mathrm{C}$ and $70{ }^{\circ} \mathrm{C}$, respectively. This result was in accordance with our previous differential scanning calorimetry (DSC) analysis on iFMDV, which also exhibited two thermal transitions at similar temperatures, the first $T_{\mathrm{m}}$ has been verified corresponding to $146 \mathrm{~S}$ dissociating into $12 \mathrm{~S}$ and the second is the further degradation of $12 \mathrm{~S} .^{5}$ The two $T_{\mathrm{m}}$ in DSF were considered the same as in DSC, and therefore the $T_{\mathrm{m} 1}$ is the most we concern.

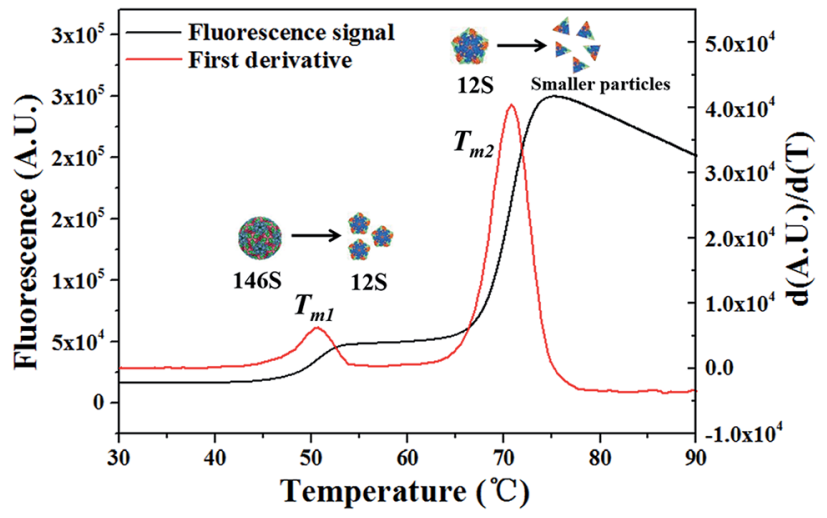

Fig. 1 Transition curve (black solid line) and its first-order derivative curve (red solid line) of FMDV $146 \mathrm{~S}$ in DSF. The fluorescence of SYPRO Orange increased upon binding to hydrophobic patches during FMDV dissociating and further denaturation of $12 \mathrm{~S}$. 
The effect of concentration of the three ILs on iFMDV thermo-stability was detected and was summed in Fig. 2. Three choline-based ILs showed different behaviours. [Cho] $\left[\mathrm{SO}_{4}\right]$ and [Cho][Cl] improved the $T_{\mathrm{m} 1}$ values in a concentration dependent manner. The $T_{\mathrm{m} 1}$ was significantly increased from $53.00 \pm$ $0.11{ }^{\circ} \mathrm{C}$ to $56.80 \pm 0.12{ }^{\circ} \mathrm{C}$ in $1 \mathrm{M}$ [Cho] $\left[\mathrm{SO}_{4}\right]$ and to $57.20 \pm$ $0.15{ }^{\circ} \mathrm{C}$ in $1 \mathrm{M}$ [Cho][Cl]. These enhancements in $T_{\mathrm{m} 1}$ value of iFMDV was more significant than stabilization strategy by amino acid mutation, which led to about $1.5{ }^{\circ} \mathrm{C}$ increase in dissociation temperature. ${ }^{6}$ While the $T_{\mathrm{m} 1}$ were decreased in the presence of $[\mathrm{Cho}]\left[\mathrm{H}_{2} \mathrm{PO}_{4}\right]$ (Fig. 2a). These results suggested [Cho] $[\mathrm{Cl}]$ and $[\mathrm{Cho}]\left[\mathrm{SO}_{4}\right]$ have the potential to stabilize $146 \mathrm{~S}$ while $[\mathrm{Cho}]\left[\mathrm{H}_{2} \mathrm{PO}_{4}\right]$ plays the opposite role. Interestingly, we also found that $[\mathrm{Cho}]\left[\mathrm{H}_{2} \mathrm{PO}_{4}\right]$ increased the $T_{\mathrm{m} 2}$ in a wild concentration range, $[\mathrm{Cho}]\left[\mathrm{SO}_{4}\right]$ firstly decreased then increased the $T_{\mathrm{m} 2}$ values as increasing its concentration, and [Cho][Cl] slightly decreased the $T_{\mathrm{m} 2}$ (Fig. 2b). This phenomenon implied complex effects of choline-based ILs on iFMDV and different stabilization mechanisms for $146 \mathrm{~S}$ and $12 \mathrm{~S}$.

To explore the effect of higher concentration of ILs on stability of iFMDV, the $T_{\mathrm{m} 1}$ values of iFMDV in ILs with concentration ranging from $1 \mathrm{M}$ up to $2 \mathrm{M}$ was measured. Results showed that changes in $T_{\mathrm{m} 1}$ values in all these three ILs of high concentration were not significant (Fig. 2c). Fig. 2d presents the size distribution of iFMDV in PB buffer and in $2 \mathrm{M}$ ILs measured by DLS. There was no obvious change in particle size distribution observed, indicating there was no apparent aggregation of iFMDV, even at such high ILs concentration. Considering the stabilizing effects and cost of ILs, 0.5 M ILs was used in the following experiments.

\section{Long-term storage stability of iFMDV particles in ILs}

To further investigate the stabilizing efficiency of choline-based ILs, the $146 \mathrm{~S}$ dissociation in $0.5 \mathrm{M}$ of three ILs at pH 7.5 during
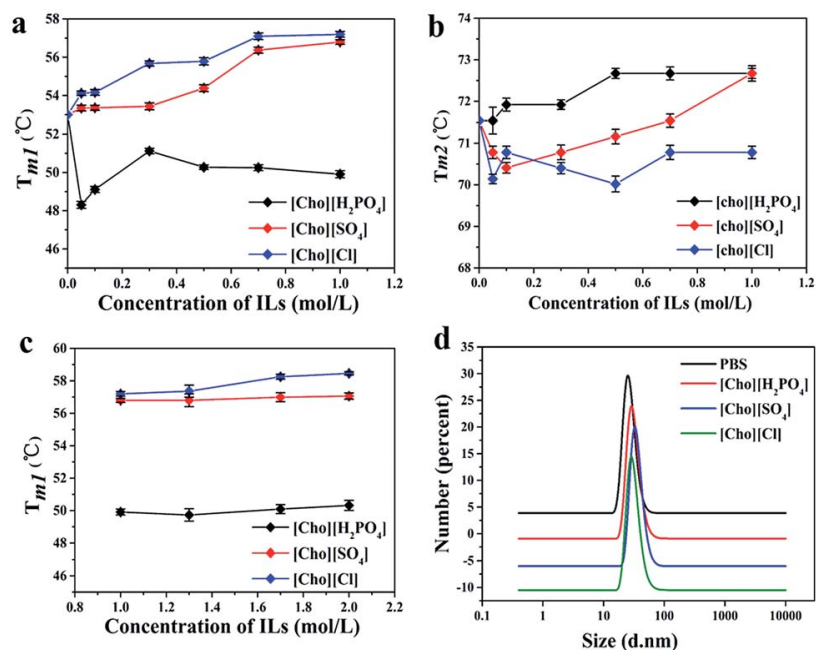

Fig. 2 (a) $T_{\mathrm{m} 1}$ and (b) $T_{\mathrm{m} 2}$ values of iFMDV in [Cho] $\left[\mathrm{H}_{2} \mathrm{PO}_{4}\right]$, [Cho] [Cl] and $[\mathrm{Cho}]\left[\mathrm{SO}_{4}\right]$ were measured by DSF at ILs concentration between 0-1 M. (c) $T_{m 1}$ values of iFMDV in three choline-based ILs at ILS concentration between 1-2 M. (d) Size distribution of iFMDV in PBS and $2 \mathrm{M}$ of ILs measured by DLS.
$4{ }^{\circ} \mathrm{C}$ storage was monitored by HPSEC and results were shown in Fig. 3a. The half-life of $146 \mathrm{~S}$, which is defined as $50 \%$ dissociation of intact $146 \mathrm{~S}$ particles, was about 10 days in $\mathrm{pH} 7.5$ PBS. Whereas, the half-life was increased to more than 1 month in $[\mathrm{Cho}][\mathrm{Cl}]$ and $[\mathrm{Cho}]\left[\mathrm{SO}_{4}\right]$, which was quite consistent with the effect of ILs on DSF results. In contract, [Cho] $\left[\mathrm{H}_{2} \mathrm{PO}_{4}\right]$ that decreased $T_{\mathrm{m} 1}$ of iFMDV also significantly shortened the halflife to only about 2 days.

Although some other stabilizers such as sucrose, BSA and sorbitol have been reported to stabilize iFMDV, ${ }^{5,24}$ using ILs as stabilizers for iFMDV have not been reported. To compare the stabilization efficiency of $[\mathrm{Cho}]\left[\mathrm{SO}_{4}\right]$ and $[\mathrm{Cho}][\mathrm{Cl}]$ with other reported stabilizing excipients for iFMDV, dissociation of iFMDV at $37{ }^{\circ} \mathrm{C}$ with $0.5 \mathrm{M}$ [Cho][ $\left.\mathrm{SO}_{4}\right], 0.5 \mathrm{M}$ [Cho][Cl], 1\% (w/v) BSA, $10 \%(\mathrm{w} / \mathrm{v})$ sorbitol, and $10 \%(\mathrm{w} / \mathrm{v})$ sucrose was investigated and compared. Results showed all these substances could improve the stability of particles when compared with PBS control (Fig. 3b). However, the two ILs were superior to other excipients, and [Cho][Cl] exhibited the best stabilization.

The particle morphology and secondary structure of iFMDV in buffer and ILs were characterized by TEM and CD spectra. As shown in Fig. 4a, after 6 days' storage at $4{ }^{\circ} \mathrm{C}$, a large number of dissociated pentamers were observed in PBS and 0.5 $\mathrm{M}$ [Cho] $\left[\mathrm{H}_{2} \mathrm{PO}_{4}\right]$ by TEM, while the majority of $146 \mathrm{~S}$ was still kept intact in $[\mathrm{Cho}]\left[\mathrm{SO}_{4}\right]$ and $[\mathrm{Cho}][\mathrm{Cl}]$ with only a few detectable pentamers. This further verified the stabilization of iFMDV integrity by [Cho] $\left[\mathrm{SO}_{4}\right]$ and [Cho][Cl] during long-term storage. Although both HPSEC and TEM showed various dissociations of $146 \mathrm{~S}$ in different ILs at 6 days, CD spectra showed only slight changes of secondary structure compared to intact 146S (Fig. 4b). This suggested the dissociation of the particles would not induce evident changes in secondary structures.

\section{Immunogenicity of iFMDV in ILs}

The assembly structure of $146 \mathrm{~S}$ had been proven most crucial to the immunogenicity of iFMDV vaccines. ${ }^{25}$ Therefore, it will be interesting to know if the increase of in vitro stability of the iFMDV will influence its immunogenicity, and whether the existence of ILs will affect immune response in vivo is also a concern. Therefore, animal experiments were conducted by
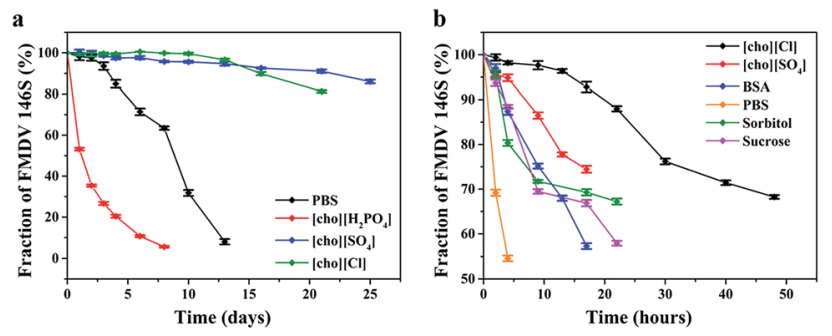

Fig. 3 (a) Fraction of iFMDV with initial $146 \mathrm{~S}$ concentration of $0.25 \mathrm{mg}$ $\mathrm{mL}^{-1}$ in PBS, 0.5 M [Cho] $\left[\mathrm{H}_{2} \mathrm{PO}_{4}\right], 0.5 \mathrm{M}[\mathrm{Cho}][\mathrm{Cl}]$ and 0.5 M [Cho] $\left[\mathrm{SO}_{4}\right]$ during storage at $4{ }^{\circ} \mathrm{C}$ at $\mathrm{pH} 7.5$. (b) Accelerated dissociation kinetic curve of $0.25 \mathrm{mg} \mathrm{mL}^{-1} \mathrm{iFMDV}$ particles in $0.5 \mathrm{M}$ [Cho] $\left[\mathrm{SO}_{4}\right], 0.5 \mathrm{M}$ [Cho] [Cl], 1\% (w/v) BSA, 10\% (w/v) sorbitol, and 10\% (w/v) sucrose at $37^{\circ} \mathrm{C}, \mathrm{pH} 7.5$. The change of $146 \mathrm{~S}$ content was monitored by HPSEC at different time intervals. 

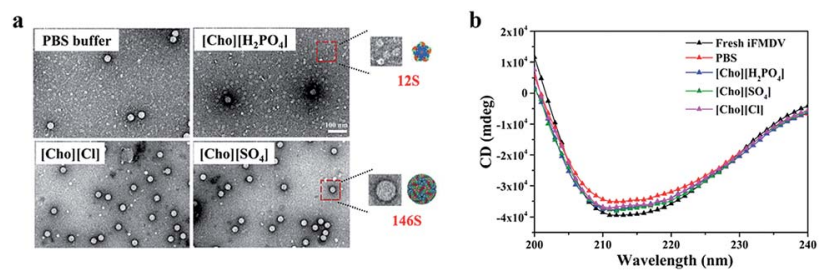

Fig. 4 (a) Negative-stain TEM images and (b) CD spectra of iFMDV particles in PBS, 0.5 M [Cho] $\left[\mathrm{H}_{2} \mathrm{PO}_{4}\right], 0.5 \mathrm{M}[\mathrm{Cho}][\mathrm{Cl}]$ and $0.5 \mathrm{M}[\mathrm{Cho}]$ $\left[\mathrm{SO}_{4}\right]$ stored at $4{ }^{\circ} \mathrm{C}$ for 6 days at $\mathrm{pH} 7.5$.

immunizing Balb/c mice with four kinds of Montanide ISA 206

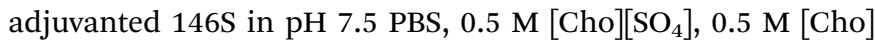
[Cl], and 0.5 $\mathrm{M}[\mathrm{Cho}]\left[\mathrm{H}_{2} \mathrm{PO}_{4}\right]$, respectively. As a negative control, $12 \mathrm{~S}$ in PBS was also inoculated in Balb/c. Antibody titers of the five groups at 14 days after the second immunization were shown in Fig. 5. The negative control 12S showed a much lower antibody titers than $146 \mathrm{~S}$ in PBS and ILs. When comparing antibody titers of $146 \mathrm{~S}$ in PBS and the three ILs groups, the antibody titers were slightly improved by [Cho] $\left[\mathrm{SO}_{4}\right]$ and [Cho] $[\mathrm{Cl}]$, and a bit lower in $[\mathrm{Cho}]\left[\mathrm{H}_{2} \mathrm{PO}_{4}\right]$, although not statistically significantly different. These suggested these choline-based ILS did not evidently affect the immunogenicity of inactivated iFMDV or immune response in vivo.

\section{Stabilizing mechanism of choline-based ILs for $146 \mathrm{~S}$}

In researches for stabilization of proteins by ILs, various mechanisms have been presented. Micaelo et al. reported ILs enhance enzymes stability and activity by modulating surrounding environment and removing water from the surface of enzymes through mechanism similar with polar organic solvents like acetonitrile. ${ }^{26}$ A protic ionic liquid (pILs) was found to attenuate the urea-induced denaturation of $\alpha$-chymotrypsin by preventing the enzyme surface from urea interaction. ${ }^{27}$ Enhanced thermal stability of $\alpha$-chymotrypsin in pILs was also

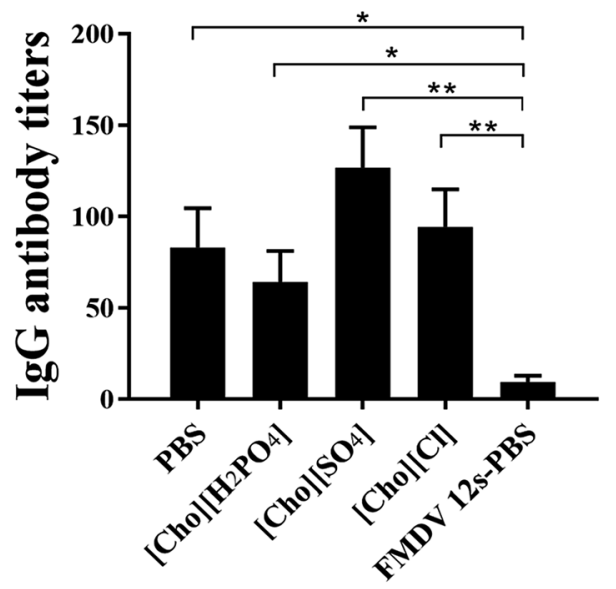

Fig. 5 iFMDV-specific antibody titers in mice serum two weeks after the second immunization by $146 \mathrm{~S}$ in $\mathrm{pH} 7.5 \mathrm{PBS}, 0.5 \mathrm{M}$ [Cho] [SO $\mathrm{S}_{4}$, $0.5 \mathrm{M}[\mathrm{Cho}][\mathrm{Cl}]$, and $0.5 \mathrm{M}[\mathrm{Cho}]\left[\mathrm{H}_{2} \mathrm{PO}_{4}\right]$, and $12 \mathrm{~S}$ in $\mathrm{pH} 7.5 \mathrm{PBS}$, respectively. Antigens were all adjuvanted with Montanide ISA 206. observed, which is considered mainly due to preferential hydration effect. ${ }^{26}$ These indicate the mechanism can be complex and divers for different proteins and ILs. Cholinebased ILs were also employed as stabilizer for lysozyme, IL-2 and mAbs, [Cho] $\left[\mathrm{H}_{2} \mathrm{PO}_{4}\right]$ was found the most effective one. ${ }^{16-18,28}$ However, results in our study showed that [Cho] $\left[\mathrm{H}_{2} \mathrm{PO}_{4}\right]$, on the contrary, accelerated the dissociation of iFMDV $146 \mathrm{~S}$ (Fig. 2a). But for iFMDV 12S, [Cho] $\left[\mathrm{H}_{2} \mathrm{PO}_{4}\right]$ exhibited somewhat stabilizing effect, which was consistent with other reports, as revealed by increased $T_{\mathrm{m} 2}$ (Fig. 2b). These implied that the mechanism of choline-based ILs stabilizing $146 \mathrm{~S}$ is quite different from $12 \mathrm{~S}$, or more generally, relatively simple proteins.

To get insight into the stabilizing mechanism of cholinebased ILs with different anion group on the 146S, the molecular structure of the capsid was analysed. The FMDV is a smallRNA virus whose icosahedral capsid contains 60 copies each of proteins VP1-VP4. The iFMDV capsids tend to dissociate into pentameric subunits $12 \mathrm{~S}$ at $\mathrm{pH}<7.0 .^{6}$ As schematically illustrated by Fig. 6 , the protonation of histidine residues $\left(\mathrm{p} K_{\mathrm{a}}=6.8\right)$ located near the inter-pentamer interface of iFMDV capsid VP2 and VP3 plays an important role in disassembly and stability of the virus. ${ }^{29}$ The electrostatic repulsion between histidine residues on structural protein VP3 and VP2, can initiate the dissociation of the capsid at $\mathrm{pH}$ lower than $\mathrm{p} K_{\mathrm{a}}$ of His (Fig. 6c). Therefore, the proton intensity around the iFMDV particles is the key factor ruling $146 \mathrm{~S}$ dissociation during storage, and the ILs with different anions would possibly alter the microenvironmental $\mathrm{pH}$ values around 146S in different way, even under the same bulk solution $\mathrm{pH}$.

To measure the $\mathrm{pH}$ around iFMDV in choline-based ILs, FITC was employed as a $\mathrm{pH}$ probe according to the ratio of fluorescence emissions at $520 \mathrm{~nm}$ from excitation at 498 and $450 \mathrm{~nm}\left(\mathrm{Ex}_{498 \mathrm{~nm}} / \mathrm{Ex}_{450 \mathrm{~nm}}\right) \cdot{ }^{30}$ An excellent linear response of $\mathrm{Ex}_{498 \mathrm{~nm}} / \mathrm{Ex}_{450 \mathrm{~nm}}$ to the solution $\mathrm{pH}$ ranging from $\mathrm{pH} 5.5$ to 8.0 was observed for the FITC-labeled iFMDV (Fig. 7a). Based on this calibration, the microenvironmental $\mathrm{pH}$ around iFMDV in the three choline-based ILs of different concentration were monitored at an identical bulk solution $\mathrm{pH}$ of 7.3. The $\mathrm{pH}$ of

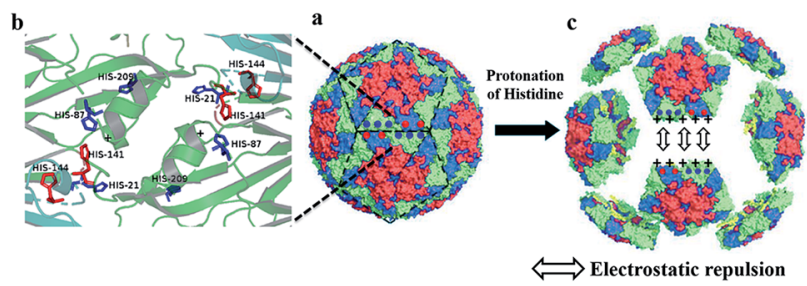

Fig. 6 Schematic illustration of protonation of the histidine residues at inter-pentamer interface trigger dissociation of FMDV particles into 12 pentameric assemblies upon lowering of $\mathrm{pH}$. (a) Surface representation of atomic models of the intact FMDV (PDB 1fod). Red: VP1; green: VP2; blue: VP3; yellow: VP4. (b) Histidine residues at inter-pentamer interface of FMDV capsids VP2 (dark blue) and VP3 (red). (c) His residues at inter-pentamer interface are in the protonated state at low $\mathrm{pH}$ and become positively charged. The inter-pentamer then dissociates by electrostatic repulsion of histidine residues and the positive end of the dipole. 
same concentration of ILs without iFMDV were also measured by FITC as a reference. The $\Delta \mathrm{pH}$, which was defined as $\mathrm{pH}$ difference between ILs with iFMDV and without iFMDV measured by FITC is presented in Fig. 3b. Despite the solution $\mathrm{pH}$ were all adjusted to 7.3, the microenvironmental $\mathrm{pH}$ around iFMDV was quite different in ILs. The microenvironmental $\mathrm{pH}$ was found higher than solution $\mathrm{pH}$ in $[\mathrm{Cho}]\left[\mathrm{SO}_{4}\right]$ and $[\mathrm{Cho}][\mathrm{Cl}]$ $(\Delta \mathrm{pH}>0)$, and the $\Delta \mathrm{pH}$ increase as the concentration of [Cho] $\left[\mathrm{SO}_{4}\right]$ and $[\mathrm{Cho}][\mathrm{Cl}]$ increased. In contrast, the microenvironmental $\mathrm{pH}$ in $[\mathrm{Cho}]\left[\mathrm{H}_{2} \mathrm{PO}_{4}\right](\Delta \mathrm{pH}<0)$ was found lower than solution $\mathrm{pH}$, and $\Delta \mathrm{pH}$ was found slightly more negative as the concentration of $[\mathrm{Cho}]\left[\mathrm{H}_{2} \mathrm{PO}_{4}\right]$ increased (Fig. 7b). These implied that microenvironmental $\mathrm{pH}$ around iFMDV was different from bulk solution $\mathrm{pH}$ in ILs and these upward or downward microenvironmental $\mathrm{pH}$ trend around iFMDV was considered to be induced by different ILs.

As we have discussed before, the proton intensity around the iFMDV particles play the most crucial role determining the stability of the assembly, decreasing proton intensity around iFMDV may be favourable to the viral stabilization. This speculation was reasonable since the $[\mathrm{Cho}]\left[\mathrm{SO}_{4}\right]$ and $[\mathrm{Cho}][\mathrm{Cl}]$ increasing the microenvironmental $\mathrm{pH}$ exhibited prominent stabilization than PBS and $[\mathrm{Cho}]\left[\mathrm{H}_{2} \mathrm{PO}_{4}\right]$. It was also confirmed by the finding that the effect of ILs concentration on $T_{\mathrm{m} 1}$ value in Fig. 2a followed the same tendency as the microenvironmental $\mathrm{pH}$ in Fig. $7 \mathrm{~b}$.

According to results and analyses above, a proposed mechanism of choline-based ILs for stabilization of $146 \mathrm{~S}$ was schematically illustrated in Fig. 8. [Cho][Cl] and [Cho] $\left[\mathrm{SO}_{4}\right]$ assist to remove protons around iFMDV in buffer, therefore prevent the protonation of histidine between the inter-pentamer interface of iFMDV. When replacing $[\mathrm{Cl}]^{-}$and $\left[\mathrm{SO}_{4}\right]^{2-}$ anions by weakly acidic $\left[\mathrm{H}_{2} \mathrm{PO}_{4}\right]^{-}$, an equilibrium was established between the two phosphate species and the "free protons": $\mathrm{H}_{2} \mathrm{PO}_{4}{ }^{-}=\mathrm{H}^{+}+$ $\mathrm{HPO}_{4}{ }^{2-}{ }^{31}$ These free protons could enter into the microenvironments around the virus, increased the proton intensity, and therefore accelerated the protonation of His residues which destabilize 146S.

The decisive role of proton intensity on dissociation 146S is helpful for understanding the inconsistency in stability of $146 \mathrm{~S}$ and $12 \mathrm{~S}$ in [Cho] $\left[\mathrm{H}_{2} \mathrm{PO}_{4}\right]$. For $12 \mathrm{~S}$ and other proteins such as enzymes, antibodies and cytokine with relative simple
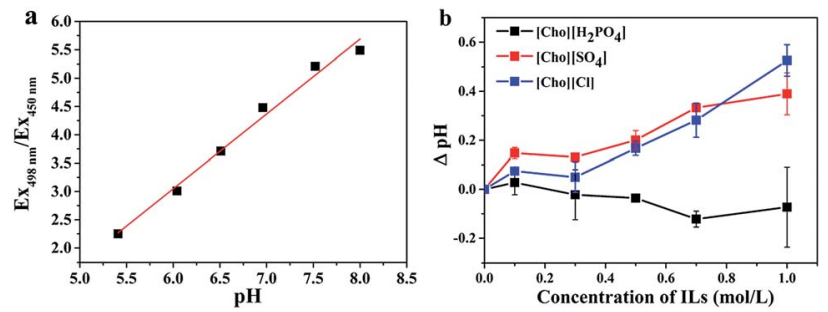

Fig. 7 (a) Linear response between the ratio of excitation at 498 and $450 \mathrm{~nm}\left(\mathrm{Ex}_{498} \mathrm{~nm} / \mathrm{Ex}_{450 \mathrm{~nm}}\right)$ and $\mathrm{pH}$ of FITC-labeled iFMDV $146 \mathrm{~S}$ solution $\left(y=1.32 x-4.87, R^{2}=0.984\right)$. (b) $\Delta \mathrm{pH}$ of FITC-labeled FMDV in different concentrations of ILs. Concentrations of ILs were set as 0 , $0.1,0.3,0.5,0.7$, and $1 \mathrm{M}$.

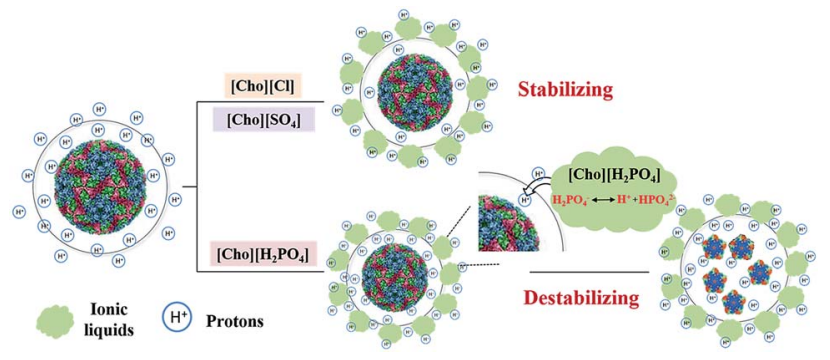

Fig. 8 Schematic depiction of stabilization mechanism of cholinebased ILs for 146S. Proton intensities around the FMDV particles in the presence of $[\mathrm{Cho}]\left[\mathrm{H}_{2} \mathrm{PO}_{4}\right],[\mathrm{Cho}][\mathrm{Cl}]$ and $[\mathrm{Cho}]\left[\mathrm{SO}_{4}\right]$ is regarded the major reason for stabilizing or destabilizing.

structure, proton intensity was not critical for their stability. Therefore, [Cho] $\left[\mathrm{H}_{2} \mathrm{PO}_{4}\right]$ stabilizing these proteins obey some other mechanism, but decreased the stability of iFMDV 146S. The dissociation mechanism dominated by protonation of His may also provide a reasonable explanation on the weak change in secondary structures upon severe $146 \mathrm{~S}$ dissociation, as indicated by CD spectra analysis (Fig. 4b). Even changes in tertiary structure during $146 \mathrm{~S}$ dissociation was rather weak as revealed by small increase of the fluorescence signal for $146 \mathrm{~S}$ dissociation in DSF analysis. While the denaturation of $12 \mathrm{~S}$ generated an enormous change of DSF signal, reflecting the severe tertiary structure change. All these observations suggested the dissociation of $146 \mathrm{~S}$ was dominated by a mechanism significantly different with other simple proteins, therefore the stabilization for $146 \mathrm{~S}$ by choline-based ILs was through a mechanism distinct from that for other proteins.

\section{Conclusions}

Stabilization of biomacromolecules with complex assembly structures is important to their biological functions but a challenge due to the unstable nature. In the present work, the three biocompatible choline-based ILs as potential stabilizers for iFMDV were studied for the first time, their effect on stability and immunogenicity of iFMDV were comprehensively studied and stabilizing mechanism for iFMDV were discussed. [Cho] [Cl] and $[\mathrm{Cho}]\left[\mathrm{SO}_{4}\right]$ were found to stabilize iFMDV and show good biocompatibility to the antigens epitope and in vivo immune response. The $T_{\mathrm{m}}$ value of $146 \mathrm{~S}$ dissociation was increased for about $4{ }^{\circ} \mathrm{C}$ by $1 \mathrm{M}$ [Cho][Cl] and [Cho] $\left[\mathrm{SO}_{4}\right]$. They also significantly prolong the half-life during long-time storage, even better than excipients generally used. [Cho] $\left[\mathrm{H}_{2} \mathrm{PO}_{4}\right]$ destabilized $146 \mathrm{~S}$ although it stabilizes other proteins. Modulation of proton intensity around iFMDV was regarded as the major mechanism for stabilizing or destabilizing $146 \mathrm{~S}$ by the three ILs. [Cho][Cl] and $[\mathrm{Cho}]\left[\mathrm{SO}_{4}\right]$ exhibited great stabilization due to their ability to remove protons from iFMDV surface. Whether other ILs with similar feature also stabilize 146S, and whether these ILs can also stabilize other virus or VLPs will be studied in future. Meanwhile, we expect the current work would promote the applications of ILs in virus and VLPs, and facilitate development of more biocompatible ILs with high safety. 


\section{Ethical statement}

This study was performed in strict accordance with the Experimental Animal-Guidelines for Ethical Review of Animal Welfare (GB/T 35892-2018) and was approved by the Committee on the Ethics of Animal Experiments of the Institute of Process Engineering at the Chinese Academy of Sciences (Beijing, China).

\section{Conflicts of interest}

There are no conflicts to declare.

\section{Acknowledgements}

The authors are thankful for financial support from the National Natural Sciences Foundation of China (No. 21808226, 21821005).

\section{Notes and references}

1 M. B. van Eldijk, L. Schoonen, J. J. L. M. Cornelissen, R. J. M. Nolte and J. C. M. van Hest, Small, 2016, 12, 24762483.

2 Y. J. Ma, R. J. M. Nolte and J. J. L. M. Cornelissen, Adv. Drug Delivery Rev., 2012, 64, 811-825.

3 L. Zhang, L. H. L. Lua, A. P. J. Middelberg, Y. Sun and N. K. Connors, Chem. Soc. Rev., 2015, 44, 8608-8618.

4 M. Yamada, K. Fukai, K. Morioka, T. Nishi, R. Yamazoe, R. Kitano, N. Shimada, K. Yoshida, T. Kanno, K. Sakamoto and M. Yamakawa, J. Vet. Med. Sci., 2018, 80, 689-700.

5 Y. L. Yang, Q. Z. Zhao, Z. J. Li, L. J. Sun, G. H. Ma, S. P. Zhang and Z. G. Su, Vaccine, 2017, 35, 2413-2419.

6 A. Kotecha, J. Seago, K. Scott, A. Burman, S. Loureiro, J. S. Ren, C. Porta, H. M. Ginn, T. Jackson, E. Perez-Martin, C. A. Siebert, G. Paul, J. T. Huiskonen, I. M. Jones, R. M. Esnouf, E. E. Fry, F. F. Maree, B. Charleston and D. I. Stuart, Nat. Struct. Mol. Biol., 2015, 22, 788-794.

7 S. Q. Liang, Y. L. Yang, L. J. Sun, Q. Z. Zhao, G. H. Ma, S. P. Zhang and Z. G. Su, Biochem. Eng. J., 2017, 124, 99-107. 8 H. Li, Y. L. Yang, Y. Zhang, S. P. Zhang, Q. Zhao, Y. Y. Zhu, X. Q. Zou, M. R. Yu, G. H. Ma and Z. G. Su, Protein Expression Purif., 2015, 113, 23-29.

9 M. M. Harmsen, H. P. Fijten, D. F. Westra and J. M. CocoMartin, Vaccine, 2011, 29, 2682-2690.

10 T. Liang, D. C. Yang, M. M. Liu, C. Sun, F. Wang, J. F. Wang, H. W. Wang, S. S. Song, G. H. Zhou and L. Yu, Arch. Virol., 2014, 159, 657-667.

11 J. Kissmann, S. B. Joshi, J. R. Haynes, L. Dokken, C. Richardson and C. R. Middaugh, J. Pharm. Sci., 2011, 100, 634-645.
12 F. He, S. B. Joshi, F. Bosman, M. Verhaeghe and C. R. Middaugh, J. Pharm. Sci., 2009, 98, 3340-3357.

13 J. Kissmann, S. F. Ausar, T. R. Foubert, J. Brock, M. H. Switzer, E. J. Detzi, T. S. Vedvick and C. R. Middaugh, J. Pharm. Sci., 2008, 97, 4208-4218.

14 N. Adawiyah, M. Moniruzzaman, S. Hawatulailaa and M. Goto, MedChemComm, 2016, 7, 1881-1897.

15 M. Smiglak, J. M. Pringle, X. Lu, L. Han, S. Zhang, H. Gao, D. R. MacFarlane and R. D. Rogers, Chem. Commun., 2014, 50, 9228-9250.

16 J. V. Rodrigues, V. Prosinecki, I. Marrucho, L. P. Rebelo and C. M. Gomes, Phys. Chem. Chem. Phys., 2011, 13, 1361413616.

17 D. M. Foureau, R. M. Vrikkis, C. P. Jones, K. D. Weaver, D. R. MacFarlane, J. C. Salo, I. H. McKillop and G. D. Elliott, Cell. Mol. Bioeng., 2012, 5, 390-401.

18 M. Reslan, V. Ranganathan, D. R. Macfarlane and V. Kayser, Chem. Commun., 2018, 54, 10622-10625.

19 A. Banerjee, K. Ibsen, T. Brown, R. Chen, C. Agatemor and S. Mitragotri, Proc. Natl. Acad. Sci. U. S. A., 2018, 115, 72967301.

20 A. Kumar and P. Venkatesu, RSC Adv., 2014, 4, 4487-4499.

21 P. Attri and P. Venkatesu, Int. J. Biol. Macromol., 2012, 51, 119-128.

22 N. Byrne, B. Rodoni, F. Constable, S. Varghese and J. H. Davis,Jr, Phys. Chem. Chem. Phys., 2012, 14, 1011910121.

23 Y. Yang, H. Li, Z. Li, Y. Zhang, S. Zhang, Y. Chen, M. Yu, G. Ma and Z. Su, Vaccine, 2015, 33, 1143-1150.

24 M. M. Harmsen, H. P. Fijten, D. F. Westra and A. Dekker, Vaccine, 2015, 33, 2477-2484.

25 M. G. Rao, G. Butchaiah and A. K. Sen, Vet. Microbiol., 1994, 39, 135-143.

26 N. M. Micaelo and C. M. Soares, J. Phys. Chem. B, 2008, 112, 2566-2572.

27 P. Attri, P. Venkatesu, A. Kumar and N. Byrne, Phys. Chem. Chem. Phys., 2011, 13, 17023.

28 B. Jagannath, S. Muthukumar and S. Prasad, Anal. Chim. Acta, 2018, 1016, 29-39.

29 F. M. Ellard, J. Drew, W. E. Blakemore, D. I. Stuart and A. M. Q. King, J. Gen. Virol., 1999, 80, 1911-1918.

30 S. M. Levitz, S. H. Nong, K. F. Seetoo, T. S. Harrison, R. A. Speizer and E. R. Simons, Infect. Immun., 1999, 67, 885-890.

31 D. R. Macfarlane, R. Vijayaraghavan, H. N. Ha, A. Izgorodin, K. D. Weaver and G. D. Elliott, Chem. Commun., 2010, 46, 7703-7705. 